Article

\title{
Seasonal Variations and Sources of Airborne Polycyclic Aromatic Hydrocarbons (PAHs) in Chengdu, China
}

\author{
Ju Yang ${ }^{1}$, Wenlai $X u^{1,2, *}$ and Huiyu Cheng ${ }^{2}$ \\ 1 State Key Laboratory of Geohazard Prevention and Geoenvironment Protection, \\ Chengdu University of Technology, Chengdu 610059, China; yangjucdut@yeah.net \\ 2 State Environmental Protection Key Laboratory of Synergetic Control and Joint Remediation for Soil \& \\ Water Pollution, Chengdu University of Technology, Chengdu 610059, China; huiyucheng@yeah.net \\ * Correspondence: xuwenlai1983@163.com; Tel.: +86-135-510-29646
}

Received: 6 January 2018; Accepted: 9 February 2018; Published: 11 February 2018

\begin{abstract}
The concentrations of polycyclic aromatic hydrocarbons (PAHs) in the air of Chengdu, a southwest city of China, were determined from March 2015 to February 2016. Here, two diagnostic ratios (DR) were determined and a principal component analysis/multiple linear regression (PCA/MLR) analysis was performed to identify the sources of PAHs during the four seasons. The gaseous and particle phase samples were analyzed separately. The sampled air had a gas-to particle ratio of 4.21 , and between $18.7 \%$ and $31.3 \%$ of the total detected PAHs were found in the particulate phase. The total concentration of all 16-PAHs combined (gas + particles) varied from 176.94 in summer to $458.95 \mathrm{ng} \cdot \mathrm{m}^{-3}$ in winter, with a mean of $300.35 \pm 176.6 \mathrm{ng} \cdot \mathrm{m}^{-3}$. In the gas phase, phenanthrene(Phe) was found at the highest concentrations in all four seasons, while benzo[b]fluoranthene $(\mathrm{BbF})$ and (in winter) chrysene $(\mathrm{Chr})$ were the highest in the particle phase. The DR of Fluroanthene (Flua)/(Flua + Pyrene (Pyr)) was higher in the gas phase than in the particle phase, while the Indeno[1,2,3-cd]pyrene(IcdP)/(IcdP + Benzo[ghi]perylene (BghiP)) ratio was more variable in the gas than that in the particle phase. The main sources for both phases were a mixture of liquid fossil fuel combustion and the burning of biomass and coal, with clear seasonal variation. Principal Component Analysis/Multiple Linear Regression (PCA/MLR) analysis identified the main PAH sources as coal burning (52\%) with motor vehicle exhaust and coke (48\%) in spring; coal (52\%), coke $(21 \%)$, and motor vehicle exhaust $(27 \%)$ in summer; coal $(47 \%)$, vehicle exhaust $(34 \%)$, and coke $(19 \%)$ in autumn; and coal (58\%) and vehicle exhaust $(42 \%)$ in winter.
\end{abstract}

Keywords: PAHs; source apportionment; diagnostic ratios; PCA/MLR

\section{Introduction}

Polycyclic aromatic hydrocarbons (PAHs) are toxic pollutants that can be distributed widely by air pollution. They are semi-volatile and persistent with different distribution characteristics according to their physicochemical properties. In polluted air, PAHs can be present both in the gas phase and bound to particles. PAHs with lower molecular weight are more volatile and, together with those that are water-soluble, are typically found in the gas phase, while PAHs with higher molecular weight and higher octanol-water partition coefficients are typically more lipophilic and are easier absorbed by particles [1]. The origin of air-borne PAHs can be natural causes (e.g., wild fires, volcanic activity), but human activity is mostly responsible [2,3]. These activities include the burning of wood and fossil fuels for industry, transport, heating, and electricity production. For control of air quality and to reduce human exposure to these toxic chemicals, the sources of PAHs need to be investigated.

For such investigations, determination of diagnostic ratios and analysis by multivariate statistics is very useful [1,4]. Multivariate statistical analysis can be performed by principal 
component analysis (PCA) or principal component combined with multiple regression (PCA/MLR). These receptor-oriented models are independent on the composition and degradation of PAHs and are widely used [5]. In China, where air pollution can be severe, a limited number of studies have been performed to identify PAHs sources by the use of receptor-oriented models. However, a comprehensive survey for emission sources of PAHs that differentiates between air-borne gas and particle phases is lacking for southwest China, where local topographic, climate conditions, and human use of energetic sources differ from those in better-studied northern areas of China.

The city of Chengdu, the capital city of Sichuan province, is typical for cities in the southwest of China. It is located in the Chengdu plain at $540 \mathrm{~m}$ elevation and is surrounded by mountains. This topography limits the migration and diffusion of pollutants from the city to surrounding areas, causing severe local air pollution. In the current study, the atmospheric concentrations of PAHs in the gas and particle phase were measured on a weekly basis during a complete year (March 2015-February 2016). Diagnostic ratios were analyzed by PCA/MLR to investigate individual PAHs in both the gas and particle phases in air in the city.

\section{Materials and Methods}

\subsection{Sample Collection}

The sampling site (E104.148937, N30.682027) was located at the university campus, approximately $15 \mathrm{~m}$ above ground level in the east of Chengdu. Samples were taken once a week, resulting in a total of 98 samples (52 gas phase samples and 52 particle phase samples).

Air samples were collected using a high-volume air sampler with an air flow rate of $0.8 \mathrm{~m}^{3} \cdot \mathrm{min}^{-1}$, an acquisition time of $24 \mathrm{~h}$, and a sampling volume of approximately $1150 \mathrm{~m}^{3}$. During sampling, the air was drawn through a glass fiber filter (GFF) $(20 \mathrm{~cm} \times 25 \mathrm{~cm})$ to collect the particles, after which it passed a cartridge containing two layers of polyurethane foam plugs (PUF) with a total length of $10 \mathrm{~cm}$ (each PUF had a length of $5.0 \mathrm{~cm}$, and a diameter of $9.5 \mathrm{~cm}$ ) to collect gas-phase compounds. After sampling, the filters were wrapped and sealed with pre-baked aluminum foil, while the plugs were placed in acetone-rinsed glass flasks, to be stored at $-35^{\circ} \mathrm{C}$ until required for analysis.

\subsection{Experimental Procedure}

The filter and plug samples were Soxhlet-extracted with dichloromethane and a mixture of acetone: hexane $(1: 1 \mathrm{v} / \mathrm{v})$ for $24 \mathrm{~h}$, respectively. Extract volumes were reduced to $5 \mathrm{~mL}$ using a rotary evaporator. For the filters, $15 \mathrm{~mL}$ hexane was first added to the solvent before the volume was reduced. The extracts were then passed through a cleaning column containing anhydrous sodium sulfate and silica gel (Merck, Darmstadt, Germany) and eluted with a mixture of dichloromethane and hexane $(1: 1 \mathrm{v} / \mathrm{v})$. The solution was rotary-evaporated again, solvent-exchanged into isooctane, and finally reduced to a volume of $1 \mathrm{~mL}$ under a gentle nitrogen gas flow. All sample solutions were kept in gas chromatography (GC) vials for analysis.

A series of 16 PAHs (Supelco Co., Bellefonte, PA, USA) have been identified by the US Environmental Protection Agency (EPA) as priority pollutants [1,6,7]. These were analyzed by gas chromatography/mass spectrometry (GC/MS) using an Agilent 6890 N GC coupled with an Agilent 5973 mass spectrometer detector. A $60 \mathrm{~m} \times 0.25 \mathrm{~mm} \times 0.25 \mu \mathrm{m}$ HP-5MS capillary column (Agilent Co., Santa Clara, CA, USA) in selected ion monitoring (SIM) mode was used. A 2.0- $\mu \mathrm{L}$ volume of sample was injected in the splitless mode. The column temperature was programmed as follows: the temperature was kept constant at $90{ }^{\circ} \mathrm{C}$ for $1 \mathrm{~min}$, then raised to $180{ }^{\circ} \mathrm{C}$ with $10^{\circ} \mathrm{C} \cdot \mathrm{min}^{-1}$ increments, kept at $180{ }^{\circ} \mathrm{C}$ for $1 \mathrm{~min}$, then increased to from 180 to $280{ }^{\circ} \mathrm{C}$ with $3{ }^{\circ} \mathrm{C} \cdot \mathrm{min}^{-1}$, and kept at $280{ }^{\circ} \mathrm{C}$ for $20 \mathrm{~min}$. Five mixed standard solutions containing the $16 \mathrm{PAHs}$ at different standard concentrations were used to spike the PUF and GFF, and recovery was tested (see below). These data were used for the calculation of PAH concentrations in the true PUF and GFF samples. The total PAHs (R16PAHs) was defined as the sum of the 16 individual compounds. 


\subsection{Quality Control}

According to the quality assurance and control method recommended by the EPA in the process of the experiment, the blank experiment and the standard recovery test were set up during the analysis of the sample. The filed blanks and the laboratory blanks were able to be detected by naphthalene (Nap), and the remaining 15 were all below the method detection limit. Therefore, blank correction was carried out in the analysis of the results.

Most PAHs were not detectable in the filed blanks and laboratory blanks, except naphthalene, which was detected at very low concentrations in some blanks. Therefore, blank correction was carried out in the analysis of the results. The average recoveries of the four surrogates were $74-104 \%$ for GFF and $63-112 \%$ for PUF. As defined by the EPA, a pre-cleaned PUF and GFF spiked with PAHs were used to determine the method detection limits (MDLs), which were calculated as the Student's $t$-value by multiplying the standard deviation (SD) of five replicate samples. With a 1151- $\mathrm{m}^{3}$ air sample, the MDLs ranged from 5 to $12 \mathrm{pg} \cdot \mathrm{m}^{-3}$. On a monthly basis, the second, downstream PUF plug $(5.0 \mathrm{~cm}$ long) was divided into a $3 \mathrm{~cm}$ upstream and a $2 \mathrm{~cm}$ downstream fragment, and these fragments were analyzed separately to check any possible leakage of gaseous PAHs. Overall, the average proportion of PAHs collected by the $2.0 \mathrm{~cm}$ downstream fragment of the second plug was $9 \pm 4 \%$ of the total gaseous PAHs collected, meaning that the two plugs combined $(10 \mathrm{~cm}$ in total) have sufficient capacity to adsorb the gaseous PAHs during the $24 \mathrm{~h}$ sampling period.

\subsection{Diagnostic Ratios}

Different fuels and different combustion or burn conditions will release different types of PAHs and in different relative ratios. Thus, the ratio of the different marker compounds depends on the emission source. Based on previous research, we calculated the following ratios: Flua/(Flua + Pyr) and IcdP/(IcdP + BghiP). These ratios were used to identify the possible sources of the detected PAHs.

The PAHs Flua, Pyr, Icdp, and BghiP have similar physicochemical properties so these were chosen to give a characteristic ratio, as they are relatively stable in the atmospheric environment $[8,9]$. When isotopic analysis methods were compared with the diagnostic ratios of Flua/(Flua + Pyr) and IcdP/(IcdP + BghiP), they pointed to similar sources $[10,11]$. Therefore, in this study we chose the ratios of Flua/(Flua + Pyr) and IcdP/(IcdP + BghiP) to analyze the sources of PAHs in the samples.

\subsection{Principal Component Analysis/Multiple Linear Regression (PCA/MLR)}

Multivariate statistical analysis was performed using the SPSS statistical software package (SPSS 13.0) with varimax rotation, and principal components (factors) with eigenvalues $>0.8$ were used to extract the possible sources.

\section{Results and Discussion}

\subsection{Concentration of Total PAHs}

Figure 1 shows the concentration variation characteristic of PAHs in the atmospheric gas phase and particle phase within a year of the sampling period. During the sampling period, atmospheric PAHs concentration in the gas phase and the particle phase of the study area shows a similar variation, with higher PAHs concentration in winter and spring and lower PAHs concentration in summer and autumn. Peak values appeared in December, January, and February.

A summary of the total PAH concentrations (the sum of 16 individual PAHs) determined in the gas and particulate phases of air collected per seasonal average are presented in Table 1. During all seasons, the total PAH content was higher in the gas than in the particulate phase, with between $18.7 \%$ and $31.3 \%$ of the total detected PAHs (gaseous plus particulate) in the latter. The average total (gaseous plus particulate) PAH concentrations varied from $176.94 \mathrm{in}$ summer to $458.95 \mathrm{ng} \cdot \mathrm{m}^{-3}$ in winter, with a yearly mean of $300.35 \pm 176.6 \mathrm{ng} \cdot \mathrm{m}^{-3}$. The concentration range of the total detected PAHs in the gas phase varied between 70.48 and $645.27 \mathrm{ng} \cdot \mathrm{m}^{-3}$ for individual samples, with a yearly average of 
$218.35 \pm 117.2 \mathrm{ng} \cdot \mathrm{m}^{-3}$; for the particulate phase the yearly average was $82.00 \pm 64.8 \mathrm{ng} \cdot \mathrm{m}^{-3}$. Thus, the majority of PAHs in the air are found in the gas phase, and the content of particle-bound PAHs is relatively low; the highest concentrations are found in winter and spring, while lower concentrations occur during summer and autumn.

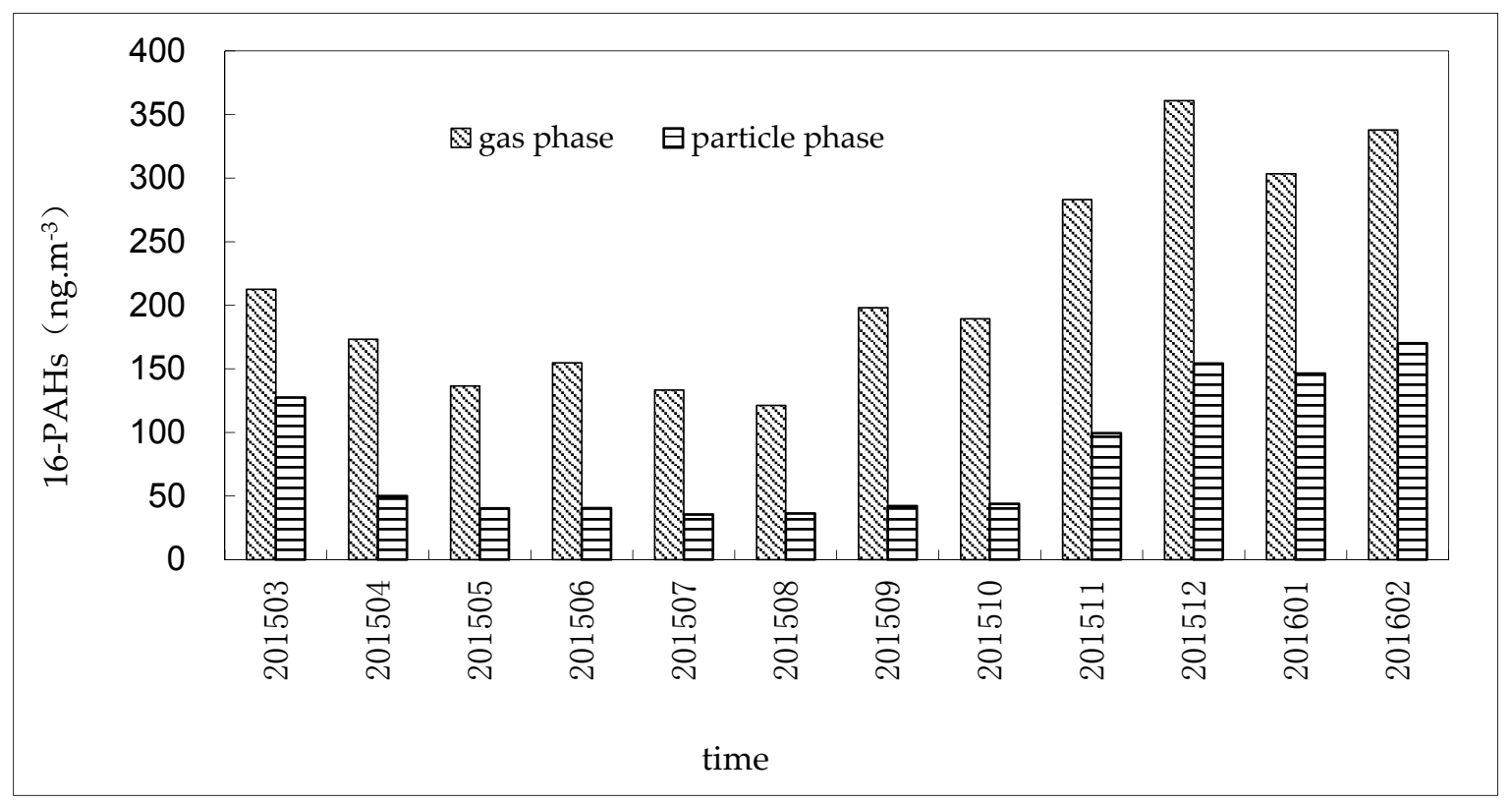

Figure 1. Atmospheric PAHs gas-particle concentration distribution in Chengdu.

Table 1. Mean concentration $\left(\mathrm{ng} \cdot \mathrm{m}^{-3}\right.$ ) and standard deviation for total, gaseous, and particulate PAHs during four different seasons of one year in air samples from Chengdu.

\begin{tabular}{cccc}
\hline Season & Gas & Particle & Total PAHs \\
\hline Spring & $228.44 \pm 90.3$ & $106.94 \pm 69.0$ & $335.38 \pm 154.5$ \\
Summer & $136.21 \pm 40.5$ & $38.53 \pm 12.7$ & $176.94 \pm 48.2$ \\
Autumn & $172.26 \pm 52.8$ & $41.58 \pm 17.5$ & $213.84 \pm 61.9$ \\
Winter & $322.76 \pm 146.6$ & $136.19 \pm 65.2$ & $458.95 \pm 207.6$ \\
Annual average & $217.09 \pm 115.9$ & $82.00 \pm 64.8$ & $300.35 \pm 176.6$ \\
\hline
\end{tabular}

The PAHs concentration ratio of gas to particles detected in Chengdu was 4.21, which is higher than those reported from a few other regions in China and abroad. For instance, a gas to particle ratio of 1.2 was reported for Harbin in China [12], and a ratio of 2.3 was detected in Seoul, Korea [13]. However, our ratio is lower than that obtained from Turkey (9.36) [14], Birmingham (5-6) [7], Guangzhou (13.2) [15] or Nanjing (8.9) in China, or Athens, Greece (5.2).

\subsection{Concentration of Individual PAHs}

The averages of individual PAH levels detected in the gas and particle phase during the four seasons are shown in Figure 2. The highest concentrations detected in the gas phase were for Phe, Fluorene (Flu), Flua, and Pyr. In particular, Phe could make up to $46.3 \%$ of total PAHs in the gas phase. Figure 2 further shows that the concentration of PAHs in the gas phase and particle phase followed similar seasonal trends with concentrations during winter $>$ spring $>$ autumn $>$ summer. PAHs with a low molecular weight, typically containing two or three organic ring structures only, dominated in the gas phase, while PAHs with higher molecular weight and more organic rings (five or six) were present in the particle phase. In the latter, BbF could make up to $16.1 \%$ of the total. Four organic ring PAHs are more likely to be enriched in the particulate phase at low temperatures, while PAHs with five or six 
organic rings are more likely to be adsorbed in particulates at high temperatures. Studies have shown that PAHs with four to six ring components mainly originate from the emissions of high temperature combustion. It is gradually distributed from the atmospheric particulates to the gas phase $[16,17]$.
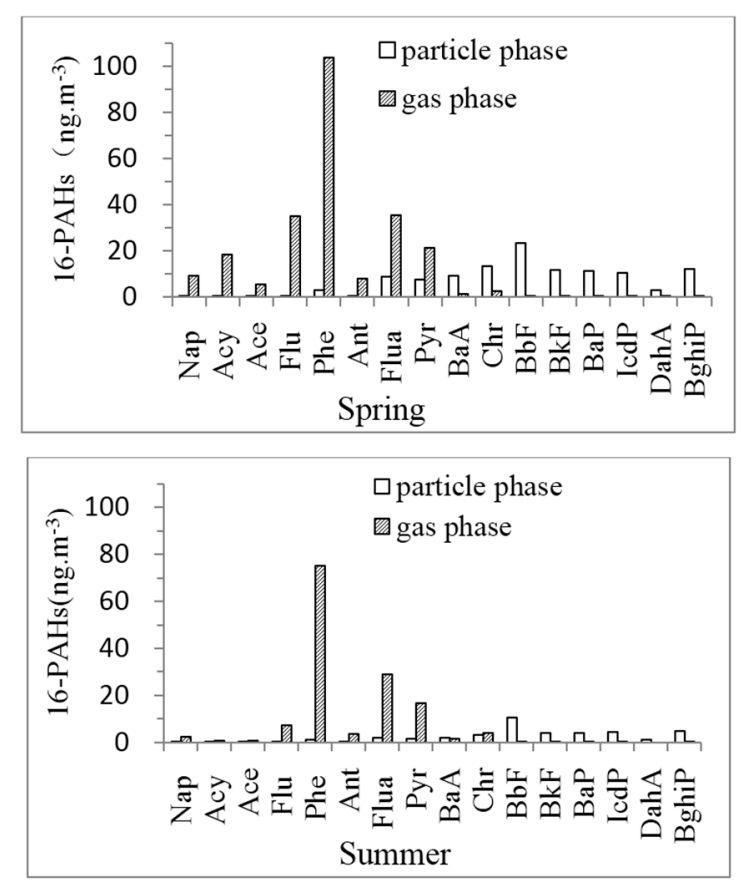
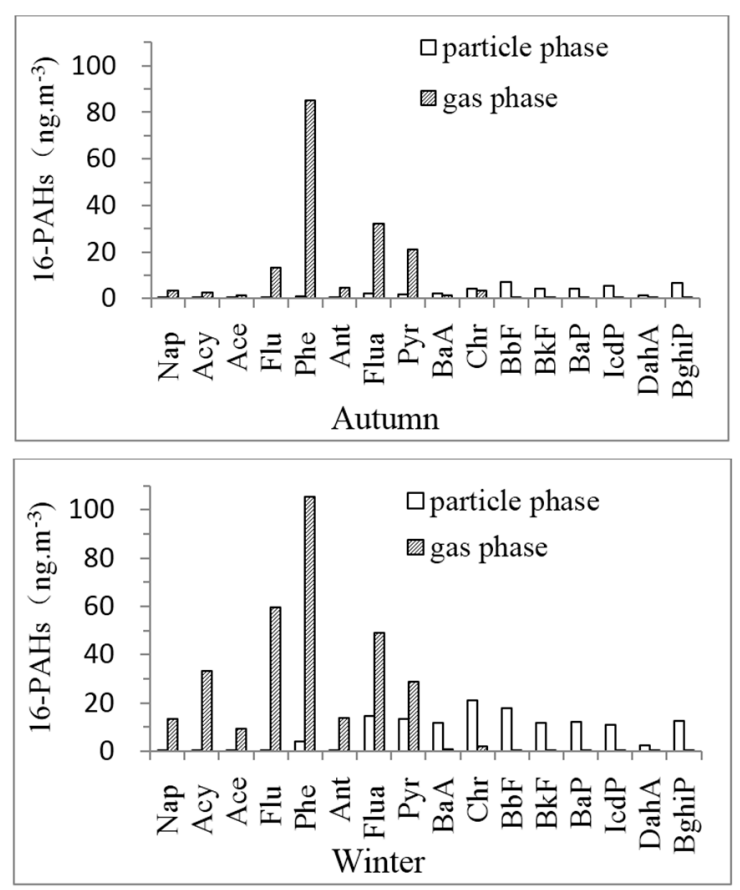

Figure 2. The concentration (ng. $\mathrm{m}^{-3}$ ) of the 16 PAHs in the gas phase and particle phase during the different seasons. The PAHs are shown in order of decreasing molecular weight. (Note: Naphthalene (Nap) Acenapthylene(Acy) Acenaphthene(Ace) Anthracene(Ant) Benzo[a]anthracene(BaA) Benzo[k]fluoranthene(BkF) Benzo[a]pyrene(BaP) Dibenz[a,h]anthracene(DahA)).

\subsection{Sources of PAHs}

\subsubsection{Diagnostic Ratios}

The possible sources of PAHs in air can be identified by diagnostic ratios of individual PAH compounds, due to their different distributions in different energy sources [18]. We determined the diagnostic ratios of Flua/(Flua + Pyr) and IcdP/(IcdP + BghiP) in the gas and particle air samples. The burning of biomass and coal typically results in values $>0.5$ for both of these ratios, while the combustion of liquid fossil fuels produce values $<0.5[1,8]$. In Figure 3 , the obtained ratios are plotted against each other, showing that gas phase samples produced significantly higher values of Flua /(Flua + Pyr) than particle samples, while the IcdP/(IcdP + BghiP) ratio was more variable for gas than for particle samples. These two ratios clearly separated gas from particle phase samples. In the particle phase, the Flua /(Flua + Pyr) ratio ranged between 0.38 and 0.58 (mean $0.54 \pm 0.03$ ) and the $\mathrm{IcdP} /(\mathrm{IcdP}+\mathrm{BghiP})$ ratio ranged between 0.29 and 0.53 (mean $0.44 \pm 0.04)$. In the gas phase, these values were $0.39-0.68,0.62 \pm 0.04$ and $0.40-0.54,0.46 \pm 0.04$, respectively. These results suggest that the PAHs were derived from mixed sources of vehicle exhaust and coal/biomass combustion. 


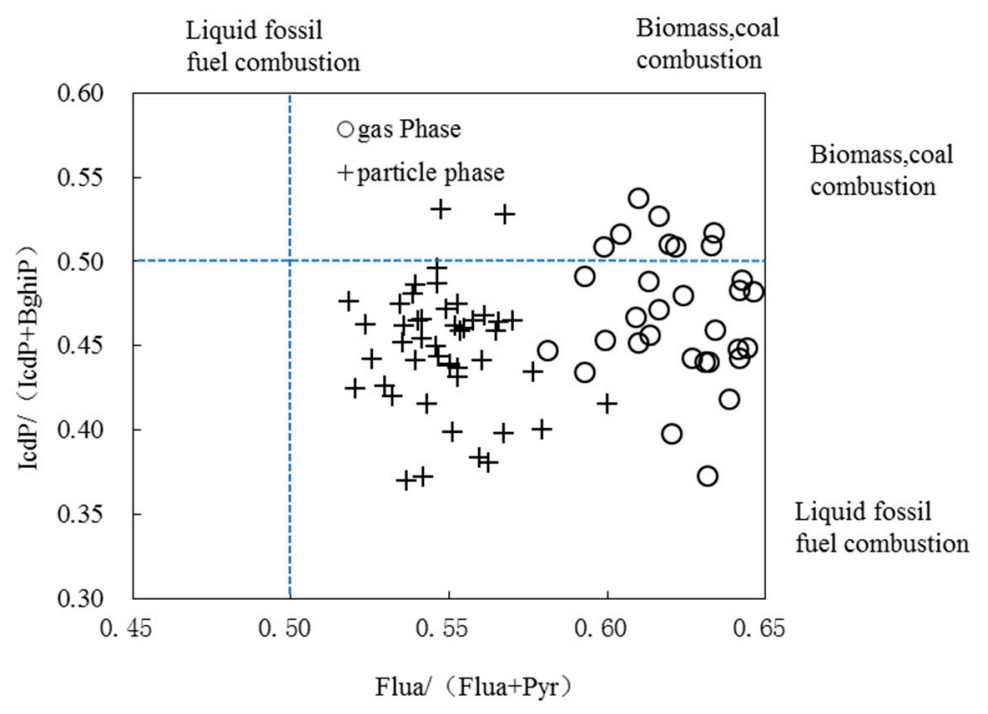

Figure 3. The diagnostic ratio of Flua/(Flua + Pyr) plotted against IcdP/(IcdP + BghiP) obtained for gas and particle samples. The division between completely liquid fossil fuel combustion sources and biomass/coal burning are indicated by dotted lines.

\subsubsection{Principal Component Analysis}

We next used PCA to identify source characteristics of the PAH concentrations. By means of factor analysis, the principal components (PCs) displaying loading values $>0.8$ were extracted with total accumulated loading accounting for more than $90 \%$ of the variance. As presented in Table 2, two or three PCs were extracted for each season. For spring, PC 1 plus PC 2 explained $92.6 \%$ of the total variance. For summer and autumn, the three retained PCs accounted for $93.6 \%$ and $95.3 \%$, respectively, of the total variance in the dataset, while the two PCs for winter contributed $94.7 \%$.

Table 2. Factor patterns of principle components (PC) 1 and 2, for individual PAHs (gas plus particle phase) in air from Chengdu, China.

\begin{tabular}{|c|c|c|c|c|c|c|c|c|c|c|}
\hline \multirow{2}{*}{ PAHs } & \multicolumn{2}{|c|}{ Spring } & \multicolumn{3}{|c|}{ Summer } & \multicolumn{3}{|c|}{ Autumn } & \multicolumn{2}{|c|}{ Winter } \\
\hline & PC1 & PC2 & PC1 & PC2 & PC3 & PC1 & PC2 & PC3 & PC1 & PC2 \\
\hline Nap & 0.227 & 0.914 & -0.149 & 0.853 & 0.359 & 0.414 & 0.817 & -0.127 & 0.747 & 0.489 \\
\hline Acy & 0.469 & 0.858 & 0.174 & 0.817 & -0.168 & 0.403 & 0.883 & -0.165 & 0.894 & 0.283 \\
\hline Ace & 0.296 & 0.853 & 0.032 & 0.935 & -0.126 & 0.448 & 0.771 & -0.216 & 0.834 & 0.464 \\
\hline Flu & 0.211 & 0.874 & -0.133 & 0.946 & 0.201 & 0.467 & 0.866 & -0.081 & 0.865 & 0.404 \\
\hline Phe & 0.857 & 0.039 & 0.250 & 0.462 & 0.752 & 0.556 & 0.458 & 0.626 & 0.288 & 0.925 \\
\hline Ant & 0.650 & 0.543 & 0.114 & -0.348 & 0.578 & 0.728 & 0.456 & 0.306 & 0.914 & 0.323 \\
\hline Flua & 0.924 & 0.414 & 0.442 & 0.129 & 0.848 & 0.493 & -0.107 & 0.831 & 0.741 & 0.589 \\
\hline Pyr & 0.887 & 0.450 & 0.472 & 0.046 & 0.840 & 0.745 & -0.357 & 0.498 & 0.833 & 0.526 \\
\hline $\mathrm{BaA}$ & 0.696 & 0.576 & 0.686 & -0.374 & 0.352 & 0.928 & -0.175 & 0.273 & 0.867 & 0.475 \\
\hline Chr & 0.895 & 0.494 & 0.818 & 0.060 & 0.569 & 0.911 & -0.246 & 0.285 & 0.741 & 0.632 \\
\hline $\mathrm{BbF}$ & 0.820 & 0.389 & 0.933 & 0.049 & 0.178 & 0.920 & -0.236 & -0.245 & 0.741 & 0.612 \\
\hline $\mathrm{BkF}$ & 0.862 & 0.512 & 0.956 & 0.000 & 0.158 & 0.851 & -0.461 & -0.276 & 0.825 & 0.527 \\
\hline $\mathrm{BaP}$ & 0.685 & 0.685 & 0.876 & 0.237 & 0.181 & 0.945 & -0.137 & -0.285 & 0.872 & 0.455 \\
\hline IcdP & 0.823 & 0.632 & 0.969 & -0.109 & 0.153 & 0.864 & -0.214 & -0.374 & 0.912 & 0.411 \\
\hline DahA & 0.779 & 0.613 & 0.921 & -0.055 & 0.309 & 0.946 & -0.199 & -0.335 & 0.859 & 0.441 \\
\hline Bghip & 0.838 & 0.522 & 0.964 & -0.071 & 0.199 & 0.853 & -0.238 & -0.379 & 0.927 & 0.379 \\
\hline Explained variance (\%) & \multicolumn{2}{|c|}{$92.6 \%$} & \multicolumn{3}{|c|}{$93.6 \%$} & \multicolumn{3}{|c|}{$95.3 \%$} & \multicolumn{2}{|c|}{$94.7 \%$} \\
\hline
\end{tabular}

PAH values mostly contributing to the PCs are shown in bold.

As shown in the table, in spring the cumulative variance contribution rate was mostly due to (in decreasing order of importance) Flua, Chr, Pyr, BkF, Phe, IcdP, Bghip, and BbF for PC1; and Nap, Flu, Acy, and Ace for PC2. Although BaA and DahA did not contribute in spring, they did so in the other 
seasons; Ant only contributed to the variance contribution rate in winter. As summarized by others, Flua, Pyr, and Chr are considered as tracers of coal combustion, but Flu and Acy are more typical tracers of coke emissions, and BkF, IcdP, and Bghip are tracers of vehicle exhaust [1,7]. We conclude that PC1 and PC2 of spring can be considered as representative of pyrogenic sources, including coal burning, vehicle emissions, and coke.

Of the PC1 extracted from the data obtained in summer, the strongest contributors (IcdP, Bhghip, and $\mathrm{BkF}$ ) point to traffic-related sources. There were over $4.28 \times 10^{6}$ vehicles in Chengdu in 2015, so automobile exhaust is a big source of PAHs in this area. In summer, when other sources related to heating are low, the relative contribution of traffic will increase, which can explain the results. A similar result was found in Dalian, China [19]. Indeed, heating-related sources such as coke and coal were only apparent in PC2 (Flu and Acy, tracers of coke oven sources) and PC3 (Flua and Pyr, tracers of coal burning). This is because these energy sources are not only used for heating but also for local industrial production.

In autumn, again three PCs were extracted, and the PAHs mainly contributing to PC1 were BaP, $\mathrm{BaA}, \mathrm{BbF}, \mathrm{DahA}$, and Bhgip. This composition is typical for a PAH source of vehicle (gasoline and diesel) exhaust emissions. PC2 is highly loaded by Flu and Acy (coke), and PC 3 is highly loaded by Flua and Phe (coal).

In winter, two PCs were extracted. The individual contributors of PC1 are weaker than those for the first principal components defined for the other seasons. This illustrates a more mixed source of the PAHs in winter with, amongst others, Bghip, Ant, and IcdP as the main tracers.

\subsubsection{Principal Component Analysis Combined with Multiple Linear Regression}

Next, PCA/MLR analysis was conducted on the data of the four seasons. Two or three principle component factors were extracted, and a multiple regression equation was calculated to determine the rate of contribution of the energy sources the PAHs represent, for the different seasons. The correlations obtained were strong, with Pearson's correlation coefficients $R^{2}>0.990$ (Table 3). For spring, factor $x_{1}$ explains $52 \%$ of the total measured PAHs, and identifies coal as the average source, with strong similarities between the two profiles $[4,20]$. This profile is predominantly loaded by Flua, Pyr, and Phe; these are typically used as markers for coal [7]. Factor $x_{2}$ is characterized by high BkF, IcdP, Bghip, Flu, and Acy, and is responsible for $48 \%$ of the measured PAHs. Flu and Acy are tracers of coke, whereas BkF, IcdP, and Bghip result from vehicle exhaust. The obtained profile is similar to the PAHs produced by vehicle exhaust and coke ovens in Dalian, a city in the northeast of China [21,22].

Table 3. Multivariate linear regression model identifying the main factors of the different seasons.

\begin{tabular}{|c|c|c|c|c|}
\hline Relevant Parameter & Multiple Regression Equation & Rate of Contribution (\%) & $p$ & $R^{2}$ \\
\hline Spring & $y=0.650 x_{1}+0.590 x_{2}$ & $\begin{array}{c}x_{1}(\text { coal }): 52 \% \\
x_{2}(\text { coke }+ \text { motor vehicle exhaust }): 48 \%\end{array}$ & 0.000 & 0.999 \\
\hline Summer & $y=0.301 x_{1}+0.232 x_{2}+0.579 x_{3}$ & $\begin{array}{c}x_{1} \text { (motor vehicle exhaust): } 27 \% \\
x_{2} \text { (coke): } 21 \% \\
x_{3} \text { (coal): } 52 \%\end{array}$ & $\begin{array}{l}0.001 \\
0.001 \\
0.000\end{array}$ & 0.991 \\
\hline Autumn & $y=0.406 x_{1}+0.340 x_{2}+0.707 x_{3}$ & $\begin{array}{c}x_{1} \text { (motor vehicle exhaust): } 34 \% \\
x_{2} \text { (coke): } 19 \% \\
x_{3} \text { (coal): } 47 \%\end{array}$ & 0.000 & 0.990 \\
\hline Winter & $y=0.724 x_{1}+0.514 x_{2}$ & $\begin{array}{c}x_{1} \text { (coal): } 58 \% \\
x_{2} \text { (motor vehicle exhaust): } 42 \%\end{array}$ & $\begin{array}{l}0.001 \\
0.000\end{array}$ & 0.998 \\
\hline
\end{tabular}

For the summer season of Chengdu, factor $x_{1}$, explaining $27 \%$ of the total measured PAHs, mainly identifies motor vehicle exhaust sources, while factor $x_{2}$ points to coke (rate of contribution $21 \%$ ) and, with a contribution to factor 3 of $52 \%$, coal burning is also identified.

During autumn, factor $x_{1}$ shows that motor vehicle exhaust is a source of PAHs, contributing $34 \%$. Exhibiting a profile similar to diesel engine emissions [21], factor $x_{2}$ points to coke (with 19\%), 
while the most likely source for factor $x_{3}$ is coal (47\%). Finally, during winter, as expected, coal burning is the most important PAH source with $58 \%$ contributing to factor $x_{1}$, which is higher than the contribution of motor vehicle exhaust (42\%) during this cold season. In the study area, atmospheric PAHs mainly originate from coal and biomass burning, followed by motor vehicle exhaust and coke. The contribution of coal combustion is different in different seasons, and the contribution of coal combustion in winter and spring to PAHs is higher than that in summer and autumn.

The PCA/MLR method is widely used to analyze the source of PAHs. For instance, Harrison et al. used this technique to identify the source of PAHs in atmosphere in Birmingham and showed that there the largest contributions were dust and motor vehicle exhaust (about $50 \%$ ), with a contribution by $\mathrm{BaP}$ of about $88 \%$ [7]. Likewise, it was shown that the contribution to PAHs in Chicago were due to coal $(48 \%)$, natural gas $(26 \%)$, motor vehicle exhaust $(9 \%)$, and coke (14\%) [1]. Our data show the effect of season on the observed distributions of PAHs, where traffic is a stronger source in summer, and coal is a stronger source in winter.

\section{Conclusions}

The diagnostic ratios of Flua/(Flua + Pyr) and IcdP/(IcdP + BghiP) were used to analyze the source of PAHs in the gas and particle air samples. The results suggest that the PAHs were derived from mixed sources of vehicle exhaust and coal/biomass combustion. Seasonal variation of sources resulting in PAHs in air collected in Chengdu, China, was detected by the application of diagnostic ratios and PCA/MLR models. Both models identified similar trends of the sources responsible for individual PAHs. The PCA/MLR model was used to estimate the contribution of each source, and clear differences were observed between seasons for relative source contributions. Coal burning was the major source $(52 \%)$ in spring, followed by traffic emissions $(48 \%)$, while in summer the main sources were coal combustion (52\%), coke ovens (21\%), and traffic emissions (27\%). During autumn coal combustion was also the most important PAH source (47\%), followed by traffic emissions (34\%), and coke ovens (19\%). Finally, during winter coal was the major source $(58 \%)$, followed by traffic emissions $(42 \%)$. These research results can provide suggestions and references for the prevention of local and nationwide air pollution.

Acknowledgments: This research is funded by Chinese National Natural Science Foundations (41502333), Sichuan Science and Technology Support Project (2017JY0141), China Postdoctoral Science Foundation (2017M610598), and the State Key Laboratory of Geohazard Prevention and Geoenvironment Protection Foundation (SKLGP2016Z019). We received the above funds for covering the costs to publish in open access.

Author Contributions: Wenlai Xu conceived and designed the experiments; Ju Yang performed the experiments; Wenlai $\mathrm{Xu}$ analyzed the data; Huiyu Cheng contributed reagents and analysis tools; Wenlai Xu wrote the paper.

Conflicts of Interest: The authors declare no conflict of interest.

\section{References}

1. Simcik, M.F.; Eisenreich, S.J.; Lioy, P.J. Source apportionment and source/sink relationships of PAHs in the coastal atmosphere of Chicago and Lake Michigan. Atmos. Environ. 1999, 33, 5071-5079. [CrossRef]

2. Wilcke, W. Polycyclic Aromatic Hydrocarbons (PAHs) in soil-a Review. J. Plant. Nutr. Soil. Sci. 2000, 163, 229-248. [CrossRef]

3. Baek, S.O.; Field, R.A.; Goldstone, M.E.; Kirk, P.W.; Lester, N.; Perry, R. A review of atmospheric polycyclic aromatic-hydrocarbons-sources, fate and behavior. Air. Soil. Pollut. 1991, 60, 279-300. [CrossRef]

4. Li, A.; Jiang, J.K.; Scheff, P.A. Application of EPA CMB 8.2 model for source apportionment of sediment PAHs in Lake Calumet, Chicago. Environ. Sci. Technol. 2003, 37, 2958-2965. [CrossRef] [PubMed]

5. Mordndi, M.T.; Daisey, J.M.; Lioyp, J. Development of amodified factor analysis/multiple regression model to apportion suspended particulate matter in a complex urban airshed. Atmos. Environ. 1987, 21, 1821-1831. [CrossRef]

6. Zhang, S.C.; Zhang, W.; Wang, K.Y. Source apportionment of atmospheric polycyclic aromatic hydrocarbons in TSP in the southeastern suburb of Beijing, China. Acta. Sci. Circum. 2007, 27, 452-458. 
7. Harrison, R.M.; Smith, D.J.T.; Luhana, L. Source apportionment of atmospheric polycyclic aromatic hydrocarbons collected from an urban location in Birmingham, UK. Environ. Sci. Technol. 1996, 30, 825-832. [CrossRef]

8. Yunker, M.B.; Macdonald, R.W.; Vingarzan, R.; Mitchell, R.H.; Goyette, D.; Sylvestre, S. PAHs in the Fraser River basin: A critical appraisal of PAH ratios as indicators of PAH source and composition. Org. Geochem. 2002, 33, 489-515. [CrossRef]

9. Zhang, Y.X.; Tao, S. Seasonal variation of polycyclic aromatic hydrocarbons (PAHs) emissions in China. Environ. Pollut. 2008, 156, 657-663. [CrossRef] [PubMed]

10. Okuda, T.; Kumata, H.; Zakaria, M.P. Source identification of Malaysian atmospheric polycyclic aromatic hydrocarbons nearby forest fires using molecular and isotopic compositions. Atmos. Environ. 2002, 36, 611-618. [CrossRef]

11. Mandalakis, M.; Tsapakis, M.; Tsoga, A. Gas-particle concentrations and distribution of aliphatic hydrocarbons, PAHs, PCBs and PCDD/Fs in the atmosphere of Athens (Greece). Atmos. Environ. 2002, 36, 4023-4035. [CrossRef]

12. Ma, W.L.; Li, Y.F.; Qi, H. Seasonal variations of sources of polycyclic aromatic hydrocarbons (PAHs) to a northeastern urban city, China. Chemosphere 2010, 79, 441-447. [CrossRef] [PubMed]

13. Park, S.S.; Kim, Y.J.; Kang, C.H. Atmospheric polycyclic aromatic hydrocarbons in Seoul, Korea. Atmos. Environ. 2002, 36, 2917-2924. [CrossRef]

14. Tasdemir, Y.; Esen, F. Urban air PAHs: Concentrations, temporal changes and gas/particle partitioning at a traffic site in Turkey. Atmos. Res. 2007, 84, 1-12. [CrossRef]

15. Li, J.; Zhang, G.; Li, X.D.; Qi, S.H.; Liu, G.Q.; Peng, X.Z. Source seasonality of polycyclic aromatic hydrocarbons (PAHs) in a subtropical city, Guangzhou, South China. Sci. Total Environ. 2006, 355, 145-155. [CrossRef] [PubMed]

16. Hong, H.S.; Yin, H.L.; Wang, X.H.; Ye, C.X. Seasonal variation of $\mathrm{PM}_{10}$-bound PAHs in the atmosphere of Xiamen, China. Atmos. Res. 2007, 85, 429-441. [CrossRef]

17. Maliszewska-Kordybach, B.; Smreczak, B.; Klimkowicz-Pawlas, A.; Terelak, H. Monitoring of the total content of polycyclic aromatic hydrocarbons (PAHs) in arable soils in Poland. Chemosphere 2008, 73, 1284-1291. [CrossRef] [PubMed]

18. Kavouras, I.G.; Koutrakis, P.; Tsapakis, M.; Lagoudaki, E.; Stephanou, E.G.; Von Baer, D.; Oyola, P. Source apportionment of urban particulate aliphatic and polynuclear aromatic hydrocarbons (PAHs) using multivariate methods. Environ. Sci. Technol. 2001, 35, 2288-2294. [CrossRef] [PubMed]

19. Tian, F.; Chen, J.; Qiao, X.; Wang, Z.; Yang, P.; Wang, D.; Ge, L. Sources and seasonal variation of atmospheric polycyclic aromatic hydrocarbons in Dalian, China: Factor analysis with non-negative constraints combined with local source fingerprints. Atmos. Environ. 2009, 43, 2747-2753. [CrossRef]

20. Zhang, Y.; Lin, Y.; Cai, J.; Liu, Y.; Zheng, M. Atmospheric PAHs in North China: Spatial distribution and sources Research article. Sci. Total Environ. 2016, 565, 994-1000. [CrossRef] [PubMed]

21. Wang, D.; Tian, F.; Yang, M.; Liu, C.; Li, Y.F. Application of positive matrix factorization to identify potential sources of PAHs in soil of Dalian, China. Environ. Pollut. 2009, 157, 1559-1564. [CrossRef] [PubMed]

22. Wang, R.; Liu, G.; Zhang, J. Variations of emission characterization of PAHs emitted from different utility boilers of coal-fired power plants and risk assessment related to atmospheric PAHs Research article. Sci. Total Environ. 2015, 538, 180-190. [CrossRef] [PubMed]

(C) 2018 by the authors. Licensee MDPI, Basel, Switzerland. This article is an open access article distributed under the terms and conditions of the Creative Commons Attribution (CC BY) license (http:/ / creativecommons.org/licenses/by/4.0/). 